\title{
Eficacia de la vacuna tetravalente contra el HPV para prevenir enfermedades anogenitales en hombres jóvenes
}

Efficacy of quadrivalent HPV vaccine to prevent anogenital disease in young males

Giuliano AR y col. N Engl J Med 2011;364:401-11

Objetivos

Evaluar la eficacia y seguridad de la vacuna HPVq (vacuna anti HPV para serotipos $6,11,16$ y 18).

\section{Diseño y lugar}

Ensayo clínico aleatorizado, controlado con placebo, doble ciego y multicéntrico (realizado en 71 centros y 18 países).

\section{Pacientes}

Se enrolaron 4.065 hombres jóvenes de entre 16 y 26 años, de los cuales 3.463 eran heterosexuales y 602 homosexuales. Como criterio de inclusión los mismos no debían presentar evidencia clínica o antecedentes de lesión o verruga genital, historia previa de vacunación contra HPV, o historial de cinco o más parejas sexuales. El seguimiento se realizó por un promedio de 2,9 años.

\section{Intervención}

El grupo intervención $(n=2.032)$ recibió tres dosis de vacuna HPVq (día 1, mes 2 y mes 6) por vía intramuscular en deltoides. Los participantes del grupo placebo $(n=2.033)$ recibieron el mismo esque- ma de aplicaciones sin el principio activo, en una presentación visualmente indistinguible.

\section{Medición de resultados principales}

La eficacia de la vacuna se consignó en terminos de reducción en la incidencia de lesiones ano-genitales externas vinculadas a los serotipos cubiertos por la vacuna: verrugas, PIN (neoplasia intraepitelial peneana) grados 1 a 3 , o cáncer de pene (resultado primario); y en términos de reducción en la incidencia de infección persistente, mediante la detección de ADN viral y la induccion de Anticuerpos anti-HPV 6/11/16/18 (resultado secundario). Se realizó análisis por intención de tratar* y por protocolo*.

\section{Resultados principales}

Los principales resultados se detallan en la tabla 1. La proporción de sujetos que informaron efectos adversos graves o que abandonaron la vacunación a causa de un efecto adverso, fue similar en ambos grupos. La mayoría de las lesiones correspondieron a condilomas acuminados. Durante el periodo de seguimiento no se detectaron casos de cáncer peneano, perianal o perineal.

Tabla 1: Eficacia de la vacuna tetravalente contra HPV

\begin{tabular}{|c|c|c|c|c|c|c|}
\hline \multirow[b]{2}{*}{ Tipo de HPV } & \multicolumn{3}{|c|}{ Vacuna cuadrivalente HPV } & \multicolumn{3}{|c|}{ Placebo } \\
\hline & Tipo de análisis & Casos & $\begin{array}{c}\text { DI } \\
\text { (no./100 pers.-año) }\end{array}$ & Casos & $\begin{array}{c}\text { DI } \\
\text { (no./100 pers.-año) }\end{array}$ & $\begin{array}{c}\text { Eficacia } \\
\% \text { (IC 95\%) }\end{array}$ \\
\hline \multicolumn{7}{|c|}{ Eficacia contra la aparición de lesiones genitales } \\
\hline \multirow[t]{2}{*}{ Cualquier tipo } & Int. tratar & 36 & 0,80 & 89 & 2,00 & $60,2(40,8$ a 73,8$)$ \\
\hline & Protocolo & 6 & 0,20 & 36 & 1,20 & $83,8(61,2$ a 94,4$)$ \\
\hline \multirow[t]{2}{*}{ Tipo 6, 11, 16, 018} & Int. tratar & 27 & 0,58 & 77 & 1,69 & $65,5(45,8$ a 78,6$)$ \\
\hline & Protocolo & 3 & 0,11 & 31 & 1,10 & $90,4(69,2$ a 98,1$)$ \\
\hline \multicolumn{7}{|c|}{ Eficacia contra infección persistente ${ }^{\varepsilon}$} \\
\hline Tipo 6, 11, 16, o 18 & Int. tratar & 148 & 3,61 & 273 & 6,92 & $47,8(36,0$ a 57,6$)$ \\
\hline
\end{tabular}

DI: densidad de incidencia*. no./100 pers.-año: número de casos por cada 100 personas seguidas durante un año. Int.tratar: intención de tratar. £ Se definió infección persistente a la detección del mismo serotipo de HPV en dos o mas muestras tomadas por isopado genital o biopsia con un intervalo de al menos seis meses.

\section{Conclusiones}

La vacuna tetravalente contra HPV previene la infección contra HPV 6, 11, 16 y 18 y el desarrollo de lesiones genitales externas asociadas en hombres entre 16 y 26 años.
Palabras claves: vacuna tetravalente contra HPV, hombres jóvenes, lesiones anogenitales, infección por HPV, cáncer de pene.

Key words: HPV quadrivalent vaccine, young men, anogenital lesions, HPV infection, penile cancer.

Fuente de financiamiento: Merck Laboratories.

\section{Comentario}

Este estudio demostró eficacia para prevenir lesiones anogenitales de cualquier tipo producidas por los serotipos HPV implicados en la vacuna. Sin embargo, al no reportarse el número de pacientes que se tuvieron en cuenta en el diseño del análisis estadístico, quedan dudas sobre los resultados arrojados por el análisis por intención de tratar, existiendo la posibilidad de un sesgo de reporte. Por otro lado, desde el punto de vista de la Salud Pública resulta cuestionable la relevancia clínica de este resultado. Conociendo la historia natural de dichas lesiones, y teniendo en cuenta que la mayoría de ellas no progresan o incluso retrogradan espontáneamente, ¿qué significancia clínica tendría prevenirlas? Evitar estas lesiones no parece constituir una indicación contundente para vacunar hombres jóvenes hasta el momento. Un punto pendiente de discusión sería el posible efecto, al vacunar hombres, sobre el desarrollo de cáncer de cuello uterino en las mujeres.
Este podría ser un buen argumento a favor de la vacunación de los hombres, si existiera un efecto rebaño* sobre las mujeres, reduciendo la transmisión entre parejas sexuales. Sin embargo, debido a la falta de evidencia científica de buena calidad con relevancia clínica en relación a este punto, y al elevado costo de la vacunación, este trabajo, al momento actual, no cambia nuestra conducta. La vacuna contra el HPV ya se encuentra disponible en Argentina, siendo recientemente anunciada su incorporación al calendario oficial para la aplicación en las niñas de 11 años, en tres dosis (0, 2 y 6 meses). Ver editorial al respecto en este número de EVIDENCIA.

\section{Conclusiones del comentador}

Al menos por ahora, la vacunación contra HPV en varones jóvenes no parece representar una buena estrategia de salud pública.

María Florencia Grande Ratti [ Servicio de Medicina Familiar y Comunitaria del Hospital Italiano de Buenos Aires

*Ver glosario maria.grande@ hospitalitaliano.org.ar ] tion and disease in males. N Engl J Med 2011;364:401-11. PMID: 21288094. 